[Bull. Agr. Chem. Soc. Japan, Vol. 24, No. 4, Suppl., p. 344 350, 1960]

\title{
Fractionation of Sugar Phosphates and Nucleotides in Potato Tubers by Ion-exchange Chromatography*
}

\author{
By Kenji Mori, Michinori Nakamura and Saburo Funahashi \\ Department of Agricultural Chemistry, the University of Tokyo, Bunkyo-ku, Tokyo \\ Received September 16, 1959
}

\begin{abstract}
Phosphate compounds in potato tubers were fractionated by ion-exchange chromatography. By the use of radio-phosphorus, the following compounds were tentatively identified to be present in potato tubers: G-1-P, G-6-P, F-6-P, FDP, PGA, AMP, UMP, ADP, UDPX, UDPG and ATP. When the tubers were stored at a low temperature, the contents of organic phosphate compounds showed a considerable increase over those of potatoes stored at a high temperature. However, the relative composition of each component was not much influenced by the storage temperature except ATP which showed a great increase at a lower temperature.
\end{abstract}

It is well established that sugar contents of potatoes stored at a low temperature are greater than those of potatoes stored at a high temperature $^{1-3)}$. It has been reported that the contents of glucose, fructose and especially sucrose increase, while the starch content decreases, when potato tubers are stored at a lower temperature; the increased amount of sugars is approximately equal to the amount of starch disappeared. These results led Arreguin-Lozano and Bonner ${ }^{1)}$ to conclude that sugars are formed from starch. The results also suggest that there may be more or less changes in the contents of sugar phosphates and uridine and adenine nucleotides, which are known to play important rôles in the interconversion of sugars in plants. Concerning fractionation and analysis of sugar phosphates in potatoes as influenced by the temperature of storage, there has been a report of ArreguinLozano and Bonner ${ }^{1}$, who claimed that there were remarkable changes in the contents of

* The experimental data in this paper are taken from a thesis submitted by $K$. Mori in partial fulfilment of the recuirements for the degree of master of agriculture in the University of Tokyo, 1959.

1) B. Arreguin-Lozano and J. Bonner, Plamt Pbysiol, 24, 720 (1949).

2) S. Schwimmer, A. Bevenue, W. J. Weston and A.L. Potter, J. Agr. Food Cbem., 2, 284 (1954).

3) K. Mori and M. Nakamura, This Bulletin, 23, 389 (1959).
G-1-P**, G-6-P and F-6-P; i. e., G-6-P content was by far the greater at a higher temperature while the reverse was true for G-1-P and F-6-P. But they had made no attempt to analyze nucleotides, because the importance of uridine nucleotides in carbohydrate metabolism was not yet known at that time. Moreover, it has become gradually clear that the barium saltalcohol fractionation method for phosphate compounds ${ }^{4}$, which was employed by these authors for sugar phosphates, is not always suitable for the quantitative separation and analysis of phosphate compounds in biological materials ${ }^{4,53}$. Accordingly, it seemed interesting to reinvestigate the contents of sugar phosphates as well as to study the nucleotide contents in potatoes stored under different temperature conditions by the use of ion-exchange chromato-

** The following abbreviations are used throughout this paper: G-1-P, glucose-1-phosphate ; G-6-P, glucose-6-phosphate ; F-6m, fructose-6-phosphate; FDP, fructose-1, 6-diphosphate; AMP, ADP and ATP, adenosine mono, di- and triphosphate, respectively; UMP, uridine monophosphate; UDPAG, uridine diphosphate acetylglucosamine; UDPG, uridine diphosphate glucose; UDPX, unidentified uridine diphosphate sugar compound; PGA, phos. phoglyceric acid; $\mathrm{P} i$, inorganic orthophosphate.

4) G.A. LePage, in W.W. Umbreit, R.H. Burris and J.F. Stauffer (eds.), Manometric techniques, p. 268. Burgess Publishing Co. (Minneapolis, 1957).

5) T. Ohmura, Nippon Nôgei-kagaku Kaishi (J. Agr. Chem. Soc. Japan), 28, 240 (1954) 
graphy, which is, at the present time, generally believed to be the most suitable for the quantitative separation and analysis of phosphate compounds in biological materials ${ }^{6,7)}$.

However, as the acid or alcoholic extract of potatoes contained very large amounts of acid impurities in contrast to a small content of phosphate compounds, it was almost impossible to fractionate and determine the latter by the usual method of ion-exchange chromatograpy. After many unsuccessful trials, the method finally adopted was the one which utilized radiophosphorus to enhance the sensitivity of the analysis of phosphate compounds. By employing this procedure, the contents of sugar phosphates as well as nucleotides in potato tubers were estimated.

\section{Principle.}

\section{EXPERIMENTAL}

A strong solution of radioactive orthophosphoric acid was injected into potato tubers. After allowing these tubers to stand for several days at prescribed temperatures to reach equilibrium, a small amount of sample was cut off from the tuber and extracted with aqueous alcohol. A small amount each of several authentic specimens of phosphate compounds, the presence of which in potato tubers were suspected, was added to the extract previously freed of alcohol. The solution thus obtained was chromatographed on a Dowex-1 column. Both chemical and physical identification of phosphate compounds and radioactivity measurement were made on fractionated eluates from the column. The presence of radioactivity accompanying a phosphate compound indicates the most probable existence of that compound in potato tubers.

\section{Materials and Methods.}

Radioactive Orthophosphoric Acid: Carrier-free $\mathrm{H}_{3}{ }^{32} \mathrm{PO}_{4}$ was obtained from the Japan Radioisotope Association.

Sugar Phosphates and Nucleotides: G-1-P, dipotassium salt ${ }^{8,9)}$; G-6-P, barium salt, prepared enzymically ${ }^{10)}$;

\footnotetext{
6) A.A. Benson, in K. Paech and M. V. Tracey (eds.), Modera methods of plant analysis, Vol. 11, p. 13I. Springer Veriag (Berlin, 1955).

7) A.A. Benson, in S.P. Colowick and N.O. Kaplan (eds.), Methods in enzymology, Vol. III, p. 110. Academic Press iNew York, 1957) .

8) R.M. McCready and W.Z. Hassid, Biochemical Preptrations, 4) 63 R.M. (1955)

9) K. Mori and M. Nakamura, This Bulletin, 23, 272 (1959). 10) Y. Inoue, K. Onodera and T. Iro, Nippon Nogei-kagaku Kaisbi, 30, 59 (1956).
}

F-6-P, barium salt ${ }^{(1)}$; FDP, barium salt ${ }^{12)}$; ATP, tetrasodium salt, crude, obtained from Schwarz Labs., Inc.; UDPG, sodium salt ${ }^{13)}$.

Methods of Analysis: Inorganic orthophosphate was determined by the method of Nakamura ${ }^{(4)}$. The phenol method of Dubois et al. ${ }^{15}$ and the resorcinol method of Roe ${ }^{16)}$ were used for the determination of total sugar phosphates and fructose phosphates, respectively, by using authentic specimens as standards. Nucleotides were determined and tentatively identified by ultraviolet spectrophotometry ${ }^{17}$ and chromatographic behaviors. Radioactivity measurements were carried out with a GeigerMüller counter attached to an Aloka decimal scaler.

Incubation of Potato Tubers: Three holes (approximately $1 \mathrm{~cm}$ deep) were cut from the surface into a potato tuber (Solanum tuberosum L. var. Irish cobbler) with a cork borer (diam. ca. $0.5 \mathrm{~cm}$.). About $0.4 \mathrm{ml}$ of a solution containing approximately $0.3 \mathrm{mC}$. of carrierfree radioactive orthophosphoric acid was put into the holes, in which were then inserted potato disks cut out previously into the cork borer and they were sealed with Scotch tape. Then, the tubers were incubated either at $30^{\circ} \mathrm{C}$ for 4.5 days or at $6^{\circ} \mathrm{C}$ for 9 days.

Preparation of the Sample Solution for Coromatography: After the incubation, the potato tubers were cut into pieces and $10 \sim 15 \mathrm{~g}$ of tissues adjacent to the holes were taken for analysis, the surface of the holes being removed beforehand. Ethanol was added to the tissues to a final concentration of $80 \%$ and the homogenized suspension was refluxed on a water-bath in order to facilitate extraction of phosphate compounds and to inactivate phosphatases. The residue was again extracted two or three times with hot $50 \%$ ethanol and finally with cold $20 \%$ ethanol ${ }^{6}$. The combined extracts were concentrated in vacuo to about $5 \mathrm{ml}$ and polysaccharides were removed by high-speed centrifugation. The latter procedure was essential to ensure a good chromatographic separation. Ten to $20 \mathrm{mg}$ each of authentic phosphate compounds were added to the solution. Removal of cations and dissolution of added phosphate compounds were performed by shaking the solution with a small amount of Amberlite IR-112 $\left(\mathrm{H}^{+}\right)$in the cold.

I1) C. Neuberg, H. Lustig and M.A. Rothenberg, Arcb. Biocbem., 3, 33 (1943:.

12) N. Ohara and M. Nakamura, in preparation.

13) R. Caputto, L.F. Leloir, C.E. Cardini and A.C. Paladini, J. Biol. Chem, 184, 333 1950).

14) M. Nakamura, Nipbon Nôgei-kagakut Kaishi, 24, 1 (1950).

15) M. Dubois, K.A. Gilles, J.K. Hamilton, P.A. Rebers and F. Smith, Anal. Corm., 28, 350 (1956).

16) J.H. Roe, J. Biol. Chem., 107, 15 (1934).

17) W.E. Cohn, in Methods in enzymology, Vol. III, p. 738. Academic Press (New York, 1957). 
Table I. Extraction of Radro-Phosphorus injected into the Potato Tubers.

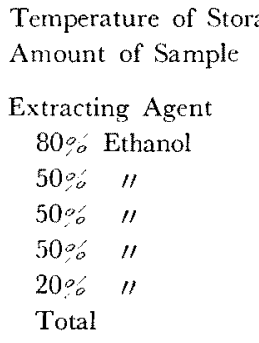

\begin{tabular}{lc} 
& \multicolumn{2}{c}{$6^{\circ} \mathrm{C}$} \\
& $15 \mathrm{~g}$ \\
Volume & Total Radioactivity \\
$65 \mathrm{ml}$ & $344 \times 10^{4} \mathrm{cpm}$ \\
35 & 570 \\
35 & 138 \\
34 & 64 \\
36 & 10 \\
205 & 1126
\end{tabular}

\begin{tabular}{ccc} 
& $30^{\circ} \mathrm{C}$ \\
\multicolumn{3}{c}{$10 \mathrm{~g}$} \\
Volume & & Total Radioactivity \\
$42 \mathrm{ml}$ & & $206 \times 10^{4}$ cpm \\
26 & 312 \\
23 & 113 \\
- & - \\
20 & 28 \\
111 & 659
\end{tabular}

Then, the pH of the solution was adjusted to 8.5 with diluted ammonia (total volume, $25 \sim 30 \mathrm{ml}$ ).

Ion-exchange Chromatography: The solution was passed through a column of Dowex-1 chloride, $0.87 \mathrm{sq}$. $\mathrm{cm} \times 11 \mathrm{~cm}, 200 \sim 400 \mathrm{mesh}$, at a flow rate of $0.5 \mathrm{ml} / \mathrm{min}$. Free sugars were removed with $200 \mathrm{ml}$ of $0.001 \mathrm{M}$ aqueous ammonia. Phosphate compounds were eluted successively according to the procedure of Khym and Cohn ${ }^{\text {(s) }}$ (flow rate, $1 \mathrm{ml} / \mathrm{min}$.). The effluent solution, fractionated into $7-\mathrm{ml}$ portions, was assayed for $\mathrm{P} i$, sugar phosphates, nucleotides and radioactivity.

\section{RESULTS}

Extraction of Phosphate Compounds from Potato Tubers: The amount of phosphorus which could be extracted by aqueous ethanol was $0.02 \sim 0.03 \%$ of fresh weight of potato tubers. The extraction pattern with successive portions of aqueous ethanol is shown in Table I. Approximately one-half or more of radio-phosphorus in the tubers remained in the residue (representing most probably phosphoproteins and nucleic acids). Total and inorganic phosphorus in the combined extracts were determined in order to enable calculations of the content of any phosphate compound in the tubers by the help of radioactivity data of that compound in question after chromatographic separation. In order to know the ratio of inorganic to organic radiophosphorus in the combined extracts, it was attempted to measure the radioactivity of the former after converting it to phosphomolybdic acid followed by extraction with isobutanol ${ }^{19)}$.

\footnotetext{
181 J.X. Khym and W.E. Cohn, J.Am. Chem. Soc., 75, 1153 (1953).

19) Y. Yoshizawa, Sukatgake (J. Japan. Biochem. Soc.), 24, $219(1953)$.
}

However, the content of $\mathrm{P} i$ thus obtained was always smaller than that obtained either by direct colorimetry or after chromatographic separation. The isobutanol extraction method seemed to be unsuitable for the determination of $\mathrm{P} i$ in the presence of a large amount of pectinlike substances.

Ion-exchange Chromatography of Phosphate Compounds: The elution pattern of phosphate compounds is shown in Fig. 1. Table II shows the total radioactivity corrected for the decay and the molar ratio of each component; the molar ratio was arbitrarily expressed by assuming UDPG to be 100 . These results indicate that there may exist G-1-P, G-6-P, F-6-P, FDP, PGA, AMP, ADP, ATP, UMP, UDPG, UDPX (most probably UDPAG) besides $\mathrm{P} i$. Although authentic specimens of AMP, ADP, UMP, and UDPAG were not added as such to the sample solution, these were present in amounts sufficient to permit detection by ultraviolet spectrophotometry. It may be most probable to assume that the former two were contained in the ATP sample and the latter two contained in the UDPG sample as contaminants, respectively. A peak which appeared just before that of ADP was assumed to be PGA from the chromatographic behavior in the solvent systems used. The content of organic phosphate increased by the low temperature treatment; a remarkable increase was observed in the contents of adenine nucleotides. There was no considerable change in the content of UDPG. Concerning sugar phosphates, the observation of Arreguin-Lozano and Bonner could not be confirmed; G-6-P was 


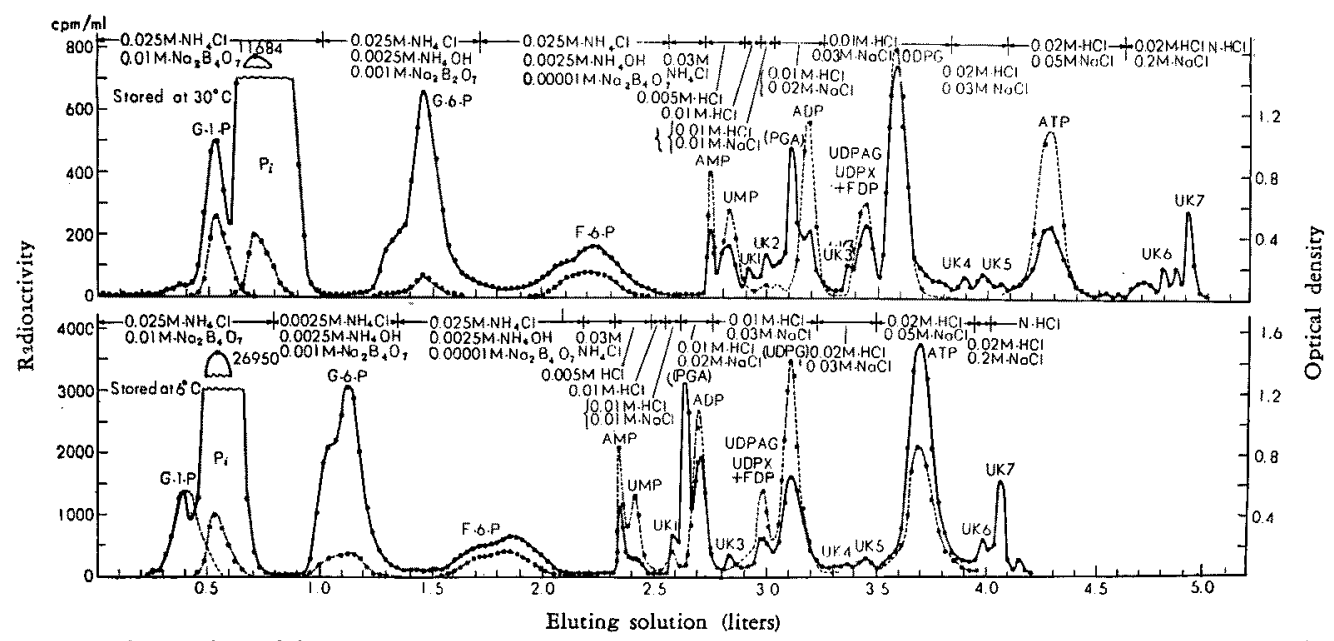

FIG. 1. Separation of Sugar Phosphates and Nucleotides in Potato Tubers by Ion-exchange Chromatography See the rext for experimental details. Solid line: radioactivity. Broken line: concentration of each compound (expressed as optical density of the solution in the appropriate assay system).

Table II. Distribution of Radio-phosphorus in Various Phosphate COMPOUNDS IN POTATO TUBERS.

\begin{tabular}{|c|c|c|c|c|}
\hline \multirow[t]{2}{*}{$\begin{array}{l}\text { Condition of storage } \\
\text { Phosphorus extracted } \\
\text { with aq. ethanol }\end{array}$} & \multicolumn{2}{|c|}{$\begin{array}{c}6^{\circ} \mathrm{C} \text { for } 9 \text { days } \\
0.022 \%\end{array}$} & \multicolumn{2}{|c|}{$\begin{array}{c}30^{\circ} \mathrm{C} \text { for } 4.5 \text { days } \\
0.024 \%\end{array}$} \\
\hline & $\begin{array}{c}\text { Radioactivity } \\
\text { cpm } \\
5695300\end{array}$ & Molar ratio & $\begin{array}{c}\text { Radioactivity } \\
\text { cpm } \\
2173700\end{array}$ & Molar ratio \\
\hline $\mathrm{Pi}$ & 3252000 & 3151.1 & 1615500 & 3496.8 \\
\hline Sugar phosphates & 1024600 & & 279900 & \\
\hline PGA & 118500 & 114.7 & 30200 & 65.4 \\
\hline G-1-P & 90200 & 87.4 & 61600 & 133.3 \\
\hline G-6-P & 573300 & 555.5 & 128400 & 278.9 \\
\hline$F-6-P$ & 242600 & 235.1 & 59700 & 129.2 \\
\hline Nucleotides & 1418700 & & 278300 & \\
\hline AMP & 73000 & 70.6 & 8500 & 18.4 \\
\hline UMP & 38200 & 37.0 & 16500 & 35.7 \\
\hline ADP & 130400 & 63.2 & 15900 & 18.4 \\
\hline FDP+UDPX & 79100 & 38.4 & 22900 & 24.9 \\
\hline UDPG & 206300 & 100.0 & 92300 & 100.0 \\
\hline ATP & 619500 & 200.1 & 47900 & 33.8 \\
\hline Unknowns & 272200 & & 74300 & \\
\hline $\begin{array}{l}\text { UK } 1 \\
\text { UK } 2\end{array}$ & 43700 & & $\begin{array}{r}5800 \\
11700\end{array}$ & \\
\hline UK 3 & 29000 & & 5800 & \\
\hline UK 4 & 24000 & & 6000 & \\
\hline UK 5 & 29300 & & 8500 & \\
\hline UK 6 & 44500 & & 8700 & \\
\hline UK 7 & 101700 & & 27800 & \\
\hline
\end{tabular}


always present more abundantly than F-6-P regardless of the temperature of storage.

With this eluting system, UDPX and FDP were eluted almost simultaneously, hence it was impossible to separate them. But approximate values for the two compounds were obtained by the following procedure (cf. Roe and Papadopoulos $\left.{ }^{20}\right)$ : FDP was precipitated from the effluent solution in the presence of added $\mathrm{P} i$ with barium acetate. The radioactivity of the supernatant (due to UDPX) was compared with that of the original solution (FDP +UDPX). The results showed that FDP was eluted slightly after UDPX and they were approximately equal in amount.

\section{DISCUSSION}

Analytical Methods: Arreguin-Lozano and Bonner ${ }^{1)}$ reported that the content of sugar phosphates in potato tubers was 3.5 5.0\% of dry weight when the analysis was carried out according to the barium salt-ethanol fractionation method of LePage ${ }^{4}$. So it was attempted at first to obtain sugar phosphates by precipitating them with barium and ethanol from the perchloric acid extract of potatoes. Then, barium was removed and the decationized solution was chromatographed on a Dowex-1 column. But actually, the phosphorus content of potatoes we could obtain in Japan was far less than that of potatoes used by the American investigators (their data show that the content of sugar phosphate-P is about $0.1 \%$ of fresh weight, while the phosphorus content of our potatoes is $0.02 \sim$ $0.03 \%$, of which more than half is $\mathrm{P} i$ ). Moreover, a considerable amount of pectin-like polysaccharides was present in our potatoes. These acid polysaccharides were the major component of the barium precipitate and interfered with subsequent chromatography.

The following methods were tested for the fractionation of phosphate compounds, but all in vain.

a) Phosphate compounds along with acid $20)$ J.H. Roe and N.M. Papadopoulos, J. Biol. Chem., 210 ,
703 (1954). polysaccharides were precipitated with barium from the perchloric acid extract. Barium salts of hexose monophosphates were extracted with water from the precipitate, since they are known to be fairly soluble in water (Tankóp ${ }^{21)}$ obtained hexose monophosphates formed in a phosphorylation reaction with pea enzymes by employing this method). It was expected that subsequent ion-exchange chromatography would reveal the composition of hexose monophosphates in potato tubers. But this method failed on account of the following two reasons. Firstly, hexose monophosphates could not be extracted completely from the barium precipitate with water.

TABLE III. EXTRACTION OF RADIOACTIVE G-6-P From BARIUM SALT PRECIPITATES CONTAINING HEXOSE MOMOPHOSPHATES.

Procedure A: The perchloric acid extract obtained from $300 \mathrm{~g}$ of potatoes was concentrated in vacuo and to the concentrated solution was added $\mathrm{G}-6-{ }^{2} \mathrm{P}$ (about $1.7 \mathrm{mg}, 1.0 \times 10^{5} \mathrm{cpm}$ ). Water-insoluble (Fraction I) and water-soluble alcohol-insoluble (Fraction II) barium precipitates were formed according to the method of LePage ${ }^{4}$. Fraction II was extracted with water.

Procedure B: $\mathrm{P} i$ was removed from the perchloric acid extract (see above) and $\mathrm{G}-6-{ }^{3} \mathrm{P}$ (about $2.0 \mathrm{mg}$, $1.2 \times 10^{5} \mathrm{cpm}$ ) was added to the concentrated filtrate. Ethanol was added to the solution to give a final concentration of $60 \%$ and the precipitate (Fraction III) was removed. The supernatant was treated with barium acetate and ethanol and the $80 \%$ ethanol-insoluble barium precipitate (Fraction IV) was extracted with water.

\section{Procedure A}

Fraction

I

II

Aq. extract

Residue

Total

Procedure B

$\begin{array}{lcr}\text { III } & \text { g } & \mathrm{cpm} \\ \text { IV } & 2.1 & 66100 \\ \text { Aq. extract } & 3.9 & 15800 \\ \quad \text { Residue } & & 32600 \\ \text { Total } & 1.8 & 114500\end{array}$

43200

19600

91600

5800

14500
21) B. Tankó, Biocbenz. J., 30, 692 (1936).
Racioactivity 28800

\section{cpm}


Table III shows the results of two recovery experiments by using radioactive G-6-32P. Secondly, polysaccharides were also dissolved in water and gave a viscous solution which was unsuitable for chromatography.

b) The perchloric acid extract was neutralized with a concentrated solution of potassium hydroxide and the resulting potassium perchlorate was removed by centrifugation in the cold. All acid substances present in the supernatant were adsorbed on a column of Amberlite IR$4 \mathrm{~B}$, acetate form. After washing the column with water, the acid substances were eluted with a sodium hydroxide solution and the phosphate compounds were precipitated as the barium salt, which, after removal of barium, was used for chromatography. The acid pectinlike substances behaved similarly as phosphate compounds in the adsorption and desorption processes. The presence of a large amount of acid impurities interfered with the adsorption of phosphate compounds on a Dowex-l column.

c) Potatoes were extracted with aqueous ethanol and after the removal of ethanol, the solution was passed through a long column of Dowex-1 (2.0 sq. $\mathrm{cm} . \times 35 \mathrm{~cm})$ according to Goodman et al. ${ }^{22}$ ) But phosphate compounds were not adsorbed completely on account of the presence of a large amount of acid impurities.

d) The barium salt precipitate obtained by the method b) was dissolved and the resulting solution was passed through a column of Dowex1 , borate form, which adsorbed not only all the phosphate compounds but also sugars and pectinlike polysaccharides. Sugars and polysaccharides were washed off from the column with a dilute sodium tetraborate solution, and then G-1-P, G-6-P and F-6-P were eluted according to the method of Goodman et al. ${ }^{22)}$ However, a good separation was not obtained. Moreover, G-6-P and nucleotides were eluted simultaneously by $0.2 \mathrm{~N}$ sodium chloride solution, because preliminary separation of sugar phosphates from the nucleotides was impossible in the case of potatoes

22) M. Goodman, A.A. Benson and M. Calvin, J. Am. Chem. Soc., 77, 4257 (1955). (see method a)) and accordingly this procedure was omitted.

An additional difficulty in these methods mentioned above is that $2 \sim 3 \mathrm{~kg}$ of potatoes must be used in order to secure a sufficient amount of each phosphate compound to be identified by chemical and physical methods, because potatoes contain only a very small amount of these compounds.

Since the separation of phosphate compounds from the acid impurities was almost impossible, it seemed advantageous to carry out analysis with a small quantity of sample which contained only a small amount of impurities to disturb neither adsorption of phosphate compounds on nor subsequent elution of them from the column. For that purpose, it was necessary to employ radio-phosphorus which would enable us to detect ultramicro quantities of each phosphate compound. So a method was devised which has been described in the experimental section. As it has already been confirmed ${ }^{3)}$ that a remarkable change in sugar composition occurs within several days under different temperature conditions, it was assumed that the incorporation of radio-phosphorus into phosphate compounds participating in the carbohydrate metabolism could also occur within the same period. But it is not guaranteed that the incorporation of radio-phosphorus proceeds at the same rate for all the phosphate compounds. So, the results thus obtained does not always represent a completely quantitative data. Nevertheless, it is possible to detect the existing phosphate compounds qualitatively, and further, to make a relative comparison concerning the composition of phosphate compounds in potatoes stored either at a high or at a low temperature.

By employing this method, it may be possible to determine the composition of phosphate compounds in such materials as sweet potatoes, beans and cereals, of which phosphate fractionation has been quite difficult because of the presence of interfering polysaccharides. It may also be possible to fractionate phosphate compounds in microorganisms, of which sample is 
difficult to be obtained in a large quantity, although it is impossible to identify each compound unequivocally by this method alone.

Relation between the Storage Temperature and the Contents of Phospate Componnds: Table IV shows the content of sugars ${ }^{32}$ and phosphate compounds in potatoes stored at a high or at a low temperature. Further details of the composition of sugar phosphates and nucleotides are shown in Table V. Concerning the content of phosphate compounds, the authors could not observe such a remarkable change as was observed in the content of sugars. This agrees with the well-known fact that the amount of an intermediate compound does not always increase even when the amount of a final product shows a remarkable increase. The presence of UDPG suggests that probably it also plays an important rôle in the biosynthesis of sucrose in potato tubers, just as is known for several plant materials (see a short review ${ }^{23}$ on this subject). Although the content of UDPG did not increase during the low temperature storage, its turnoverrate might have been accelerated owing to the increased amount of ATP. Anyway, the composition of phosphate compounds in fresh potato tubers was not much influenced by the temperature of storage. This is quite contrary to Arreguin-Lozano and Bonner" who obtained their data on dried materials, employing another method of analysis.

23) M. Nakamura, This Bulletin, 23, 398 (1959).
Table IV. The Contents of Carbohydrates AND AqUEOUS ETHANOL-SOLUBLE PHOSPHATE

COMPOUNDS IN POTATO TUBERS AS INFLUENCED BY THE TEMPERATURE OF STORAGE

Temperature of storage $\quad 6^{\circ} \mathrm{C} \quad 30^{\circ} \mathrm{C}$

$\begin{array}{lll}\text { Starch } & 12.0 & 11.3\end{array}$

$\begin{array}{lll}\text { Sugars } & 1.62 & 0.31\end{array}$

$\begin{array}{lll}\text { Sucrose } & 1.12 & 0.28\end{array}$

Fructose $\quad 0.25 \quad 0.005$

Glucose $\quad 0.25 \quad 0.024$

Total P soluble in aq. ethanol $0.022 \quad 0.024$

$\begin{array}{lll}\mathrm{Pi} & 0.012 & 0.018\end{array}$

$\begin{array}{lll}\text { Sugar phosphate-P } & 0.004 & 0.003\end{array}$

$\begin{array}{lll}\text { Nucleotide-P } & 0.006 & 0.003\end{array}$

The figures in the table are given in percentage of fresh weight.

TABLE V. RELATIVE CONTENTS OF SUGAR PHOSPHATES AND NUCLEOTIDES IN POTATO TUBERS

Temperature of storage $\quad 6^{\circ} \mathrm{C} \quad 30^{\circ} \mathrm{C}$

$\begin{array}{lll}\text { Sugar phosphates } & \mathbf{1 0 0 . 0} & \mathbf{1 0 0 . 0}\end{array}$

$\begin{array}{lll}P G A & 11.4 & 10.8\end{array}$

$\begin{array}{lll}\text { G-1-P } & 8.9 & 22.0\end{array}$

$\begin{array}{lll}\text { G-6-P } & 56.0 & 45.8\end{array}$

$\begin{array}{lll}F-6-P & 23.7 & 21.4\end{array}$

$\begin{array}{lll}\text { Nucleotides } & \mathbf{1 0 0 . 0} & \mathbf{1 0 0 . 0}\end{array}$

$\begin{array}{lll}\text { AMP } & 5.0 & 3.0\end{array}$

$\begin{array}{lll}\text { UMP } & 2.5 & 6.0\end{array}$

$\begin{array}{lll}\text { ADP } & 9.9 & 5.7\end{array}$

$\begin{array}{lll}\text { UDPX +FDP } & 5.5 & 8.2\end{array}$

$\begin{array}{lll}\text { UDPG } & 14.5 & 33.2\end{array}$

$\begin{array}{lll}\text { ATP } & 43.5 & 17.2\end{array}$

$\begin{array}{lll}\text { Unidentified } & 19.1 & 26.7\end{array}$

Results are given in percentage of total sugar phosphates or total nucleotides, tespectively. 